Review

\title{
Exploring the Resource Value of Transvaal Red Milk Wood (Mimusops zeyheri) for Food Security and Sustainability: An Appraisal of Existing Evidence
}

\author{
Abiodun Olusola Omotayo ${ }^{1}$, Enioluwa Jonathan Ijatuyi ${ }^{2}$, Adebayo Isaiah Ogunniyi ${ }^{3}$ \\ and Adeyemi Oladapo Aremu 1,4,*D \\ 1 Food Security and Safety Niche Area, Faculty of Natural and Agricultural Sciences, North-West University, \\ Private Bag X2046, Mmabatho 2745, North West Province, South Africa; 25301284@nwu.ac.za \\ 2 Department of Agricultural Economics and Extension, North-West University, Private Bag \\ X2046, Mmabatho 2790, North West Province, South Africa; 24818879@student.g.nwu.ac.za \\ 3 International Food Policy Research Institute (IFPRI), Abuja 901101, Nigeria; a.ogunniyi@cgiar.org \\ 4 Indigenous Knowledge Systems Centre, Faculty of Natural and Agricultural Sciences, North-West \\ University, Private Bag X2046, Mmabatho 2745, North West Province, South Africa \\ * Correspondence: Oladapo.Aremu@nwu.ac.za; Tel.: +27-18-389-2573
}

Received: 25 September 2020; Accepted: 29 October 2020; Published: 4 November 2020

\begin{abstract}
Many African countries are endowed with rich biodiversity with enormous nutritional and economic prospects, but the majority of these resources are not fully harnessed. Exploring these neglected resources, for example, the Transvaal red milkwood tree [(Mimusops zeyheri) Sond. family: Sapotaceae] is of paramount importance for food and nutritional security as well as economic prosperity. This review provides a critical appraisal of the nutritional and health benefits as well as the economic potential of Mimusops zeyheri. The plant is known for its diverse uses among rural communities. In folk medicine, the decoction from the bark and leaves of Mimusops zeyheri are used for treating wounds and ulcers, while the root is used as an infusion taken to treat candidiasis and other health issues. The nutritional profile of the fruit tree is similar to popular exotic fruits and richer in vitamin $C$ when compared to guava and orange. Mimusops zeyheri is a rich source of vitamins, protein, and fatty acids. Based on the rich chemical pool, especially in the fruit and seeds, it has the potential to provide an accessible, readily available, and affordable enriched functional food with valuable health benefits. However, the successful exploration of Mimusops zeyheri for food security and sustainability requires multidisciplinary research. This will help achieve the envisaged food-nutrition security and poverty alleviation potential of the plant, especially among local communities.
\end{abstract}

Keywords: ethnobotanical uses; functional food; hidden hunger; micronutrients; indigenous fruit; phytochemicals; sapotaceae; sustainability; traditional food

\section{Introduction}

Combating malnutrition and poverty remains key in the face of the increasing global population as more than 820 million individuals (translating into one out of every nine people) in the world faced hunger in 2018. This highlights the immense challenge of achieving the United Nations Sustainable Development Goal (UN SDG Agenda 2030) number 2, which targets zero hunger by 2030 [1]. In Africa, an estimated $20 \%$ of the population is chronically undernourished (in terms of dietary and energy supply), making the continent a key region with a high prevalence of hunger [2]. Currently, Africa is lagging in the drive to meet the goals of ending hunger and ensuring access to food for all [3]. In addition, micro- and macro-nutrient deficiencies, as well as ill-health, remain major concerns, especially in rural communities [4]. This explains the importance of understanding the constraints 
faced by rural households in achieving food security and good health as well as economic liberation and development $[5,6]$. As a result, exploring opportunities on how undervalued and neglected fruit trees could contribute toward achieving UN SDG Agenda 2030, particularly Goal 2: zero hunger remains pertinent [7-10].

In southern Africa, the problem of food insecurity and ill-health remains prevalent. Specifically, inaccessibility and low financial capacity/purchasing power to afford the popular commercially available fruits. This problem remains common in rural communities where the diets mainly consist of monotonous foods, mainly starchy, and a few legume staples [11]. Thus, there should be more focus on promoting indigenous fruit trees with food and nutrition potential as these species thrive well in their natural environment [12]. The southern African region is endowed with high biodiversity, which has the potential to contribute and strengthen the food system to meet the nutritional needs of the population. The biodiversity potential can be explored and harnessed to improve food security in the region and Africa at large $[13,14]$. Furthermore, the diversity of diets via exploring indigenous fruit trees including Mimusops zeyheri (Transvaal red milkwood tree) could serve as alternative sources of nutrition, with health and socio-economic benefits.

Currently, the limited information on the nutritional and health value of Mimusops zeyheri remains fragmented. The availability and critical appraisal of existing knowledge on the fruit tree have the potential to contribute toward mitigating malnutrition and food insecurity in the southern African region and beyond. Therefore, this review explored the nutritional and health benefits as well as the economic potential of the underutilized Mimusops zeyheri as a fruit tree for potential sustainability. The following questions were explored in this review:

- What are the nutritional and ethnomedicinal uses of Mimusops zeyheri?

- What are the challenges associated with the potential commercialization and sustainability of Mimusops zeyheri?

- How can the economic potential of Mimusops zeyheri be fully explored?

\section{Materials and Methods}

Following the approach described by Moher et al. [15], the Preferred Reporting Items for Systematic Reviews and Meta-Analyses (PRISMA) was used in the selection of articles in this review. We explored various online databases, dissertations/thesis, and reports using the library of the North-West University. A thorough search was conducted primarily by using search engines such as Scopus, Web of Science (WOS), and PubMeb, some other quick checks were conducted on Google Scholar, Web of Science, and Science Direct using the following terms and phrases: "Mimusops zeyheri", "Transvaal red milkwood", "nutritional value composition of Transvaal red milkwood", "ethnomedicinal importance of the Mimusops zeyheri", "uses of Mimusops zeyheri" and "description of Transvaal red milkwood". For the current review, the search was limited to southern Africa with a literature search period (years) from 1968 to 2020 (August).

In this review, studies that fit the inclusion criteria were downloaded to assess the content. Four emergent themes were identified and categorized as (i) description and ecology of Mimusops zeyheri; (ii) uses of Mimusops zeyheri; (iii) challenges; and (iv) prospects of Mimusops zeyheri (Table 1). In cases where articles covered more than one of these themes, categories were assigned based on the theme that was most comprehensively addressed in the research questions or findings of the respective article. The process of article selection, summarization, and coding was performed using Microsoft Excel and Word, resulting in an expected minimum variability. 
Table 1. Selection criteria for scientific publications used in the current review.

\begin{tabular}{|c|c|}
\hline Exclusion Criteria & Explanation \\
\hline Undervalued African plants & Articles on various edible and non-edible fruit plants. \\
\hline Undervalued Southern African plants & Articles on various edible fruits \\
\hline History and horticulture & $\begin{array}{l}\text { Articles on archaeological evidence, historic use, } \\
\text { domestication, and cultivation of wild edible fruits }\end{array}$ \\
\hline Chemical composition & $\begin{array}{l}\text { Articles on chemical and nutrient composition, } \\
\text { medicinal use of edible fruits }\end{array}$ \\
\hline Non-edible uses & Articles describing uses of wild fruits other than food \\
\hline \multicolumn{2}{|l|}{ Inclusion Criteria } \\
\hline $\begin{array}{l}\text { Primary study subject is resource value of } \\
\text { Mimusops zeyheri fruit tree }\end{array}$ & $\begin{array}{l}\text { Studies on the uses, nutritional composition, benefits, } \\
\text { and prospects of Mimusops zeyheri }\end{array}$ \\
\hline Description and ecology & $\begin{array}{l}\text { Articles on regional diversity, ecological dynamics, } \\
\text { taxonomy, morphology, and distribution of Mimusops } \\
\text { zeyheri }\end{array}$ \\
\hline Diverse uses & $\begin{array}{l}\text { Articles documenting the ethnomedicinal, nutritional, } \\
\text { biological, phytochemicals, and economic uses of } \\
\text { Mimusops zeyheri }\end{array}$ \\
\hline Challenges & $\begin{array}{l}\text { Issues relating to delay in commercialization of the } \\
\text { Mimusops zeyheri }\end{array}$ \\
\hline Prospects & $\begin{array}{l}\text { Articles documenting food value chain, trade, } \\
\text { markets, and supply chains, policy, and interventions. }\end{array}$ \\
\hline
\end{tabular}

A total of 186 scientific publications were retrieved that focused on Mimusops zeyheri and related indigenous fruits. Finally, an estimated 33\% (59) of the scientific publications were eligible and included in the current review (Figure 1). 

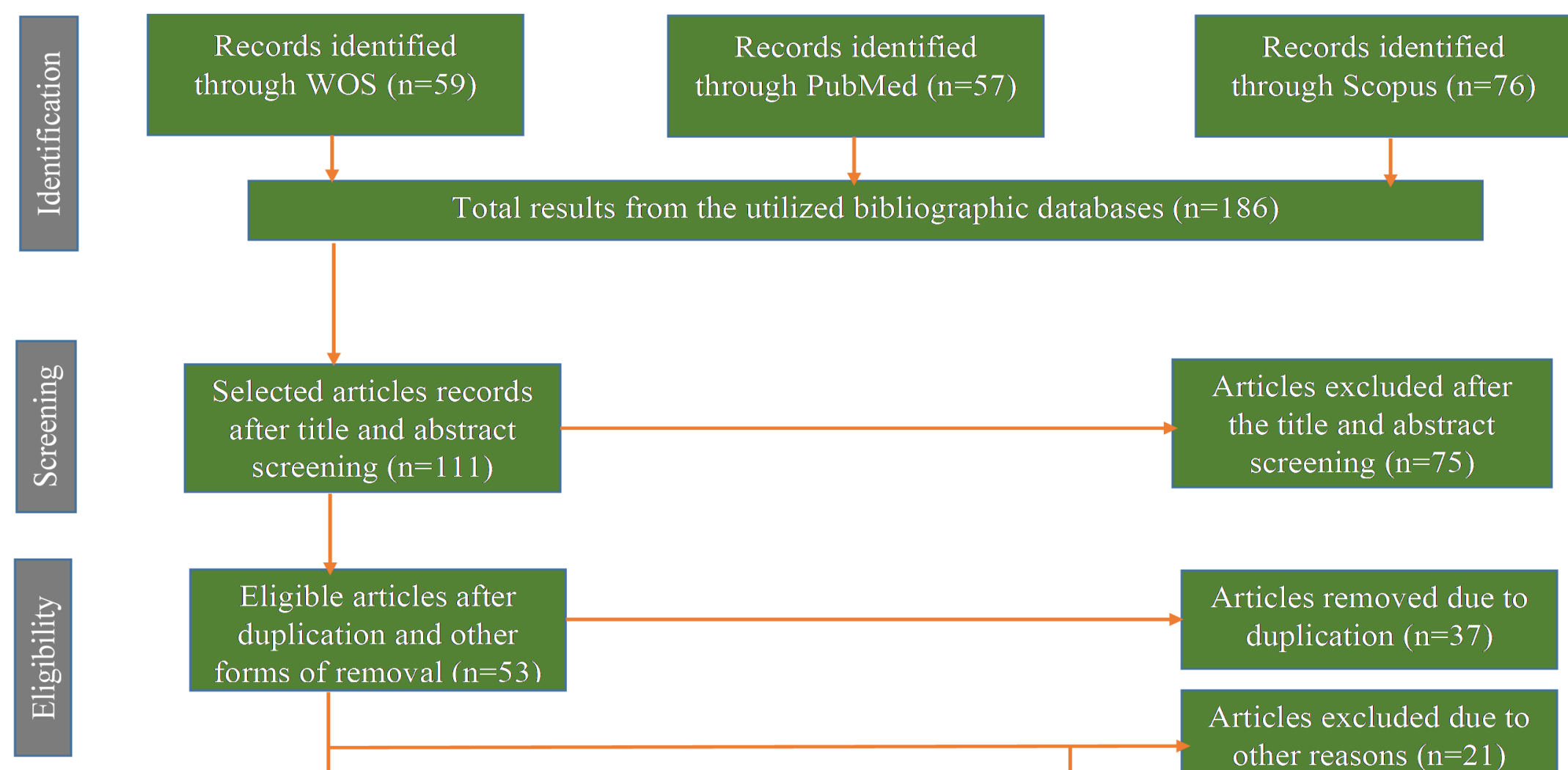

forms of removal $(n=53$

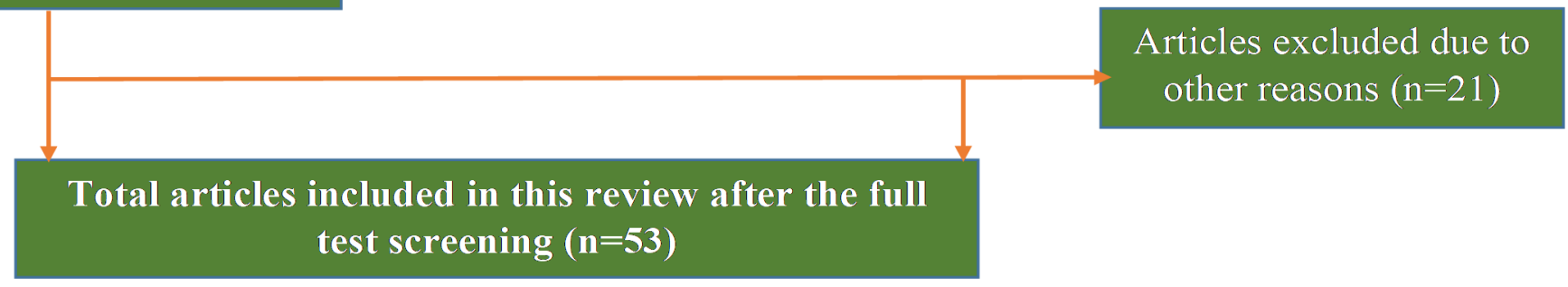

Figure 1. Preferred Reporting Items for Systematic Reviews and Meta-Analyses (PRISMA) flow diagram for the exclusion and inclusion of articles in the current review. 


\section{Taxonomy, Morphology, and Distribution of Mimusops zeyheri}

Mimusops zeyheri is a perennial fruit tree and a member of the family Sapotaceae and the common names include Transvaal red milkwood (English), Moepel (Afrikaans), Mmupudu (Northern Sotho), Umpushane (Zulu), Mubululu (Venda) and Mgamba kapu (Swati) [16]. It is a medium-sized tree ranging from $15-25 \mathrm{~m}$ high and the bark is grey to dark brown [16]. The leaves are glossy and arranged spirally, stipules are absent, and the petiole is $0.5-3.5 \mathrm{~cm}$ long [16]. The fruit is yellow-orange, $4.5 \mathrm{~cm}$ long at maturity, with 1-2 seeds that are shiny, but pale brown with a small circular basal scar.

The tree occurs in several southern African countries including South Africa, the Kingdom of Eswatini (Swaziland), Botswana, Lesotho, Namibia, Mozambique, and Zimbabwe $[17,18]$. As shown in Figure 2, its distribution extends to other parts of tropical Africa. Mimusops zeyheri occurs in open, dry, and bushveld woodland $[19,20]$. It is suited for cultivation in low to medium-altitude areas of summer rainfall where frost is minimal or absent and can withstand various soil and climate conditions [21]. In larger gardens and open spaces, Mimusops zeyheri is easily cultivated and best used as a reliable shade and used as a shelter for birds and other animals [22]. Furthermore, Mimusops zeyheri can tolerate freezing without damage and it requires little maintenance (six or more hours of daily sunlight and a minimal amount of water to survive). 


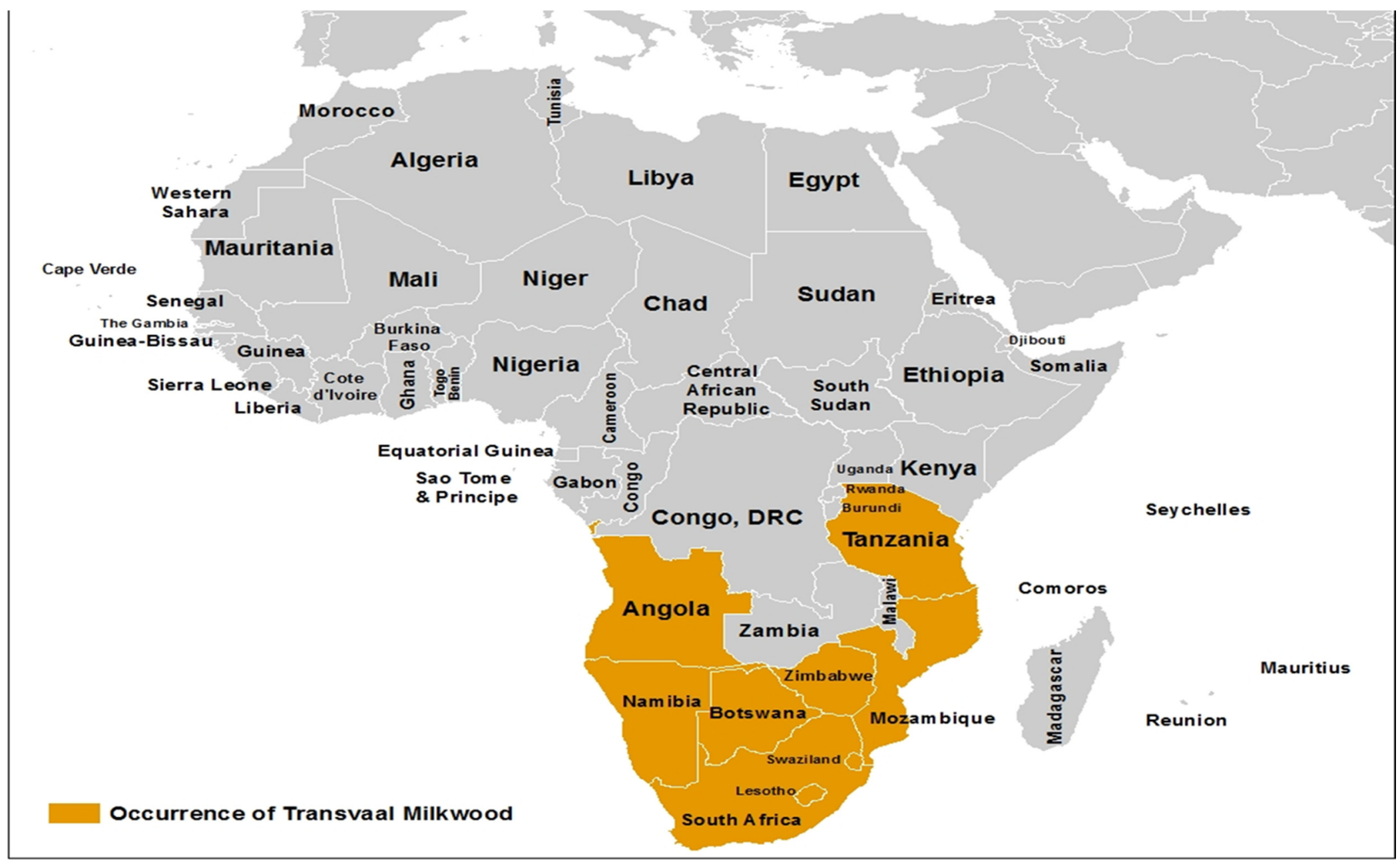

Figure 2. Occurrence and distribution of Transvaal red milkwood (Mimusops zeyheri) in Africa. 


\section{Diverse Uses of Mimusops zeyheri}

The continuous increase in the human population remains a key cause for concern in terms of meeting the daily food, nutritional, and medicinal requirements, especially in developing countries. Therefore, documenting the benefits and potential of Mimusops zeyheri is important from nutrition and health as well as ethnomedicinal perspectives. This is also relevant for the perception and socio-economic benefits of the potential consumers for this undervalued fruit tree. Some of these uses are discussed in the following sections.

\subsection{Ethno-Medicinal Applications}

In traditional medicine, Mimusops zeyheri extracts are used for different purposes. For instance, Lapeña et al. [23] observed that the bark of Mimusops zeyheri is used to treat wounds and sores by the Zulus of South Africa. It is also a local remedy for sexually transmitted infections (STIs), especially gonorrhea [24]. In the Kingdom of Eswatini (Swaziland), a root infusion is taken to treat candidiasis and a bark decoction is a traditional remedy for treating wounds and ulcers [25]. The ground seeds of the fruit tree are used as a teeth whitening agent [26]. Mimusops zeyheri is considered an effective remedy for treating inflammation, bleeding gums, tuberculosis, and diverse sexually transmitted diseases [25]. The bark and root of Mimusops zeyheri are used to treat different forms of wounds and ulcers. The root of Mimusops zeyheri is used as an infusion for treating candidiasis, tuberculosis, weight loss, womb problems, and STIs [27,28].

\subsection{Nutritional Content}

Evidence of the diverse nutritional pool existing in different parts of Mimusops zeyheri has been demonstrated by different researchers (Table 2). According to Wilson and Downs [29], the fruit of Mimusops zeyheri contains high concentrations of sucrose, glucose, and fructose. The orange color of the fruit is an indication of its high beta-carotene content. The leaves of Mimusops zeyheri contain 10 elements such as nitrogen, phosphorous, potassium, calcium, and magnesium [28]. The quantity for these 10 elements was within the permissible limits, thereby suggesting its safety [25]. Analysis of the fruit revealed varying levels of carbohydrates and ash content [30-32]. Also, the seeds of Mimusops zeyheri are considered as a dietary energy supplement and oil source [33,34].

Analysis of the seeds revealed the presence of different mineral elements including calcium and phosphorus, organic matter, crude protein, and ash content [33]. Based on the proximate analysis, dry matter, organic matter, and ash content constituted $91.1 \%, 88.3 \%$, and $2.8 \%$ of the seed mass, respectively. Chivandi et al. [33] identified 17 amino acids in the seeds of Mimusops zeyheri, which accounted for an estimated $97 \%$ of the crude protein content $(9.3 \%)$. Glutamic acid, which was the major amino acid constituted approximately $13.8 \%$ of the crude protein. Furthermore, oleic and palmitic acids were the only lipids that were detected. Neutral detergent fiber and acid detergent fiber constituted $33.2 \%$ and $15.3 \%$, respectively [32,33].

Mimusops zeyheri contains varying concentrations of the different compounds (Table 2). Particularly, the plant is a rich source of vitamins ( $\mathrm{A}=$ retinol, $\mathrm{C}=$ ascorbic acid and $\mathrm{E})$, amino acids, and fatty acids [33,34]. In addition, the medium fiber content in the Mimusops zeyheri seeds could be useful in providing the necessary bulk for the facilitation of normal gastrointestinal motility in the food and feeds of humans and animals, respectively [33]. Based on the presence of vitamin E, Mimusops zeyheri seeds could potentially be used as a dietary ingredient to increase the systemic antioxidant pool, thus protecting the body against potential oxidative damage.

The lipid in Mimusops zeyheri seeds is similar to that found in soybean (Glycine max). The lipid content of $21.3 \%$ is comparable to that of soybean, which has between 15 and $25 \%$ lipid content [32]. However, the oil content of Mimusops zeyheri seeds is lower than that of the cottonseed (Gossipium hirstum), which has 35-40\% oil content [33]. Furthermore, the oleic acid content of Mimusops zeyheri seed oil (85\% of lipid yield (84.59) is high when compared to the $70-78 \%$ oleic acid in Marula 
tree (Sclerocarya birrea) kernel oil and 63\% oleic acid in red sour plum (Ximenia caffra) kernel oil [35]. Interestingly, these two (2) aforementioned indigenous fruit trees flourish in a similar environment as Mimusops zeyheri in southern Africa. The vitamin C content in Mimusops zeyheri fruit range from $50-80 \mathrm{mg} / \mathrm{g}$ fresh fruit and this content is relatively higher when compared to guava, which is an exotic fruit with $20 \mathrm{mg} / \mathrm{g}$ vitamin C [21,36].

Table 2. Mineral, proximate, and amino acid composition for different parts of Mimusops zeyheri.

\begin{tabular}{|c|c|c|c|}
\hline Plant Part & Nutrient Composition & Composition (\%) & Reference \\
\hline \multirow[t]{10}{*}{ Leaves } & Nitrogen & 6.33 & [25] \\
\hline & Phosphorous & 0.33 & \\
\hline & potassium & 1.25 & \\
\hline & Calcium & 0.39 & \\
\hline & Magnesium & 0.06 & \\
\hline & Zinc & 0.0029 & \\
\hline & Copper & 0.0014 & \\
\hline & Iron & 0.0409 & \\
\hline & Aluminum & 0.007407 & \\
\hline & Manganese & 0.005185 & \\
\hline \multirow[t]{5}{*}{ Fruit } & Dry matter & 91.10 & {$[33]$} \\
\hline & Organic matter & 83.30 & \\
\hline & Protein & 9.30 & \\
\hline & Ash content & $2.80-4.1$ & \\
\hline & Carbohydrates & 2.0 & [25] \\
\hline \multirow[t]{19}{*}{ Seeds } & Mineral & Mean value (mg per $100 \mathrm{~g}$ ) & [33] \\
\hline & Calcium & 587.4 & \\
\hline & Magnesium & 102.3 & \\
\hline & Phosphorus & 110.37 & \\
\hline & Proximate component & Mean value (g/kg) & [33] \\
\hline & Dry matter & 911 & \\
\hline & Organic matter & 883.39 & \\
\hline & Crude protein & 93.45 & \\
\hline & Ether extract & 256.12 & \\
\hline & Lipid yield & 212.5 & \\
\hline & Ash & 27.61 & \\
\hline & Fiber fraction $(\mathrm{g} / \mathrm{kg})$ & Mean & [33] \\
\hline & Neutral detergent fiber & 332.46 & \\
\hline & Acid detergent fiber & 153.41 & \\
\hline & Fatty acid & Percentage (\%) & [33] \\
\hline & 16:0 (palmitic acid) & 15.25 & \\
\hline & 18:1n9 (oleic acid) & 84.59 & \\
\hline & Vitamin & $\mu \mathrm{g} / \mathrm{g}$ & [33] \\
\hline & Vitamin E & 1.97 & \\
\hline
\end{tabular}

\subsection{Phytochemicals and Biological Properties of Mimusops zeyheri}

Mimusops zeyheri is a member of the family Sapotaceae, which are well-known for their wide range of phytochemicals, especially saponins, flavonoids, and polyphenolics [37]. Currently, the biological activities of Mimusops zeyheri are relatively scarce, however, studies on members of the genus Mimusops have demonstrated antifungal, gastro-protective, and antinociceptive properties [37].

\subsection{Miscellaneous Uses}

Other uses of Mimusops zeyheri have been documented in areas where the species exists. The importance of the fruit and pulp of Mimusops zeyheri for the production of jelly, alcoholic, 
and non-alcoholic beverages have been indicated [7]. These products are currently sold in rural and urban open markets, thereby contributing to the economic status of rural households [33,38]. Mimusops zeyheri is believed to improve soil fertility and this is a good contribution toward environmental sustainability as this reduces the cost of agricultural production [26,38]. In addition, the latex from the tree is used as a pesticide and the dried pulp can stay long, stored, and for consumption during winter [39]. Furthermore, Mimusops zeyheri is a useful multipurpose tree, which could be economically useful for furniture and other carpentry purposes. It is also a good horticultural tree for shade, energy, fencing, and ornamental purposes [25].

Based on the study by Chivandi, Davidson, and Erlwanger [35], Mimusops zeyheri has enormous economic and environmental benefits for rural communities through the sales of seedlings and/or fruits and combating land degradation. In addition, Ripple et al. [39] identified the seeds of Mimusops zeyheri as a potential source of calcium, which could be useful for human and animal nutrition requirements.

\section{Challenges Associated with Potential Commercialization of Mimusops zeyheri}

In recent decades, the increasing importance of indigenous fruits as a source of nutrition security has been recognized. However, there are challenges associated with the production of many indigenous fruit trees including Mimusops zeyheri [34]. Identifying the challenge(s) is the first step in the attempt to devise potential solutions to overcome these bottlenecks. Some of the challenges currently affecting the potential commercialization of Mimusops zeyheri fruit are highlighted below.

\subsection{Inadequate Information on the Effective Cultivation Protocols and Agronomic Aspects}

The propagation and establishment of Mimusops zeyheri plantations are important for its economic development. Presently, the cultivation of indigenous fruit trees including Mimusops zeyheri remains an unpopular investment when compared to exotic fruits. Mimusops zeyheri predominantly exists in the wild, which may be linked to the inadequate knowledge that currently exists on their propagation. These trees usually remain in the vegetative propagation state for a long duration before flowering and fruiting. The longevity in the maturation of the Mimusops zeyheri fruit tree will make this unattractive to smallholder farmers, who need a regular income for their livelihood and economic survival. According to Akinnifesi et al. [40,41], the reduction of fruiting time for wild fruit trees will strongly encourage investment and interest from stakeholders. Therefore, investment focused on the elucidation and shortening of the reproductive cycle and development of Mimusops zeyheri remains essential.

\subsection{Inadequate Information on the Biological Efficacy, Therapeutically Value-Added Products with Commercial Prospect}

Presently, Mimusops zeyheri has several uses in folk medicine $[25,28,30]$, but the majority of these lack scientific evidence based on responses in biological systems. The inadequate evidence-based data to support the biological potential is a major challenge that hinders the commercialization of the plant. The global spread of various diseases such as cardiovascular disease, cancer, and diabetes calls for the exploration of more natural resources including plant-based therapeutic agent(s). However, studies on the biological efficacy of Mimusops zeyheri including the ideal preparation and processing methods are currently inadequate.

\subsection{Lack of Holistic Research Approach, Inadequate Political Will, and Policy Framework}

A major challenge associated with Mimusops zeyheri is related to awareness, research, political, and socio-economic inadequacies. There is currently inadequate knowledge of several important aspects such as breeding, trait-selection, storability, and shelf-life of Mimusops zeyheri fruit. The limited knowledge on its shelf life, ambient conditions, and longevity during preservation under cold storage negatively affects the commercialization potential for this plant.

Given that Mimusops zeyheri is widely consumed by wild animals due to its sweetness, uncontrolled grazing is another major challenge mitigating its exploration. Other concerns include the high 
exploitation and the indiscriminate harvesting of Mimusops zeyheri as fuel, expansion of settlements and agriculture land, and collection of rootstocks for grafting [25]. The ineffective implementation of existing legislation for the protection and management of many forest trees has contributed to the challenges facing Mimusops zeyheri. For instance, Lapeña, Turdieva, Noriega, and Ayad [23] indicated that many decision-makers are reluctant to enact laws that protect wild plants.

According to Baldermann et al. [42], inefficiency in production, storing, and processing of the seeds together with a lack of the baseline knowledge of the nutritional potential negatively affect the acceptance, utilization, and value addition of many wild fruits. The fruit species is known for its slow growth [16], which may be a major deterrent to investment by commercial farmers. Despite the hardy nature of Mimusops zeyheri, it serves as a host for invasive fruit flies [43], thereby threatening its commercial prospect.

\section{Prospects of Unlocking the Potential of Mimusops zeyheri}

\subsection{Production of New Products with Diverse Applications}

The high tolerance of Mimusops zeyheri to drought, salt, and resistant to root-knot nematodes can be employed in agriculture for combating the menace of pests and diseases in plants [21,26]. In addition, the exploration of the seeds for oils can be pursued. Extensive research on Mimusops zeyheri may result in the development of a wide range of cosmetic products while the gel can be useful in the pharmaceutical sector for novel drug delivery systems $[44,45]$. To enhance the potential to develop new products for both humans and animals, researchers need to focus more on the biological, phytochemicals, and nutritional content of Mimusops zeyheri. As highlighted by Leakey [46], the successful domestication of indigenous species can enhance its potential in local, regional, and international markets and contribute to the bio-economy.

\subsection{Devising an Effective Value Chain}

To unlock the potential of Mimusops zeyheri, an effective value chain highlighting the sequence and critical activities from the production to the marketing stage of the fruit tree and its product is proposed (Figure 3). The development of cultivation, preharvest, and postharvest protocols to enhance the production of indigenous plants for consumption will impact the four pillars of food security, namely access, supply, availability, and utilization, which is essential for a food secured country [47]. The key-players required for the value chain of Mimusops zeyheri will include a wide range of stakeholders such as farmers, transporters, wholesalers, and retailers as well as the consumers. Presently, the sales of Mimusops zeyheri serve as a marginal portion of livelihood among smallholder farmers who harvest from the wild population [36]. Rural communities with potential for cultivating this fruit tree are plagued with prevailing subsistence farming, perhaps due to poor financial strength or lack of essential farm inputs, which happens in a cyclical order and continually.

\subsection{Efficient Agro-Processing}

As described by Mhazo et al. [48], agro-processing involves activities that transform agricultural commodities into different forms that improve handling, increase shelf-life, and add value to the final product. Efficient agro-processing aligned with the drive for the modernization of agriculture and food production systems in Africa [49], thereby enhancing the income and livelihood of households in rural communities. Therefore, the development of small-scale Mimusops zeyheri agro-processing enterprises could initiate the path toward the commercialization of Mimusops zeyheri and associated products. This type of approach is known to reduce waste of fresh produce, and increase the participation of rural households in commercial economies [50]. Agro-processing of Mimusops zeyheri can contribute to sustainable livelihoods through improved incomes, employment, food availability, nutrition, and social and cultural well-being of the rural populace. Small-scale food processing activities represent a potential source of livelihood for many poor people in developing countries. 
The overall potential of agro-processing of Mimusops zeyheri is huge as it is capable of:

(a) Increasing the value of the output of poor farmers thus, higher returns and improved livelihood;

(b) Expanding market opportunities for the farmers;

(c) Extending the shelf-life and improving the palatability of the fruit;

(d) Increasing diversity of value-added products;

(e) Enhancing food security by reducing food losses while increasing availability and accessibility;

(f) Overcoming seasonality and perishability constraints; and

(g) Empowering women who are often more involved in agro-processing activities than men.

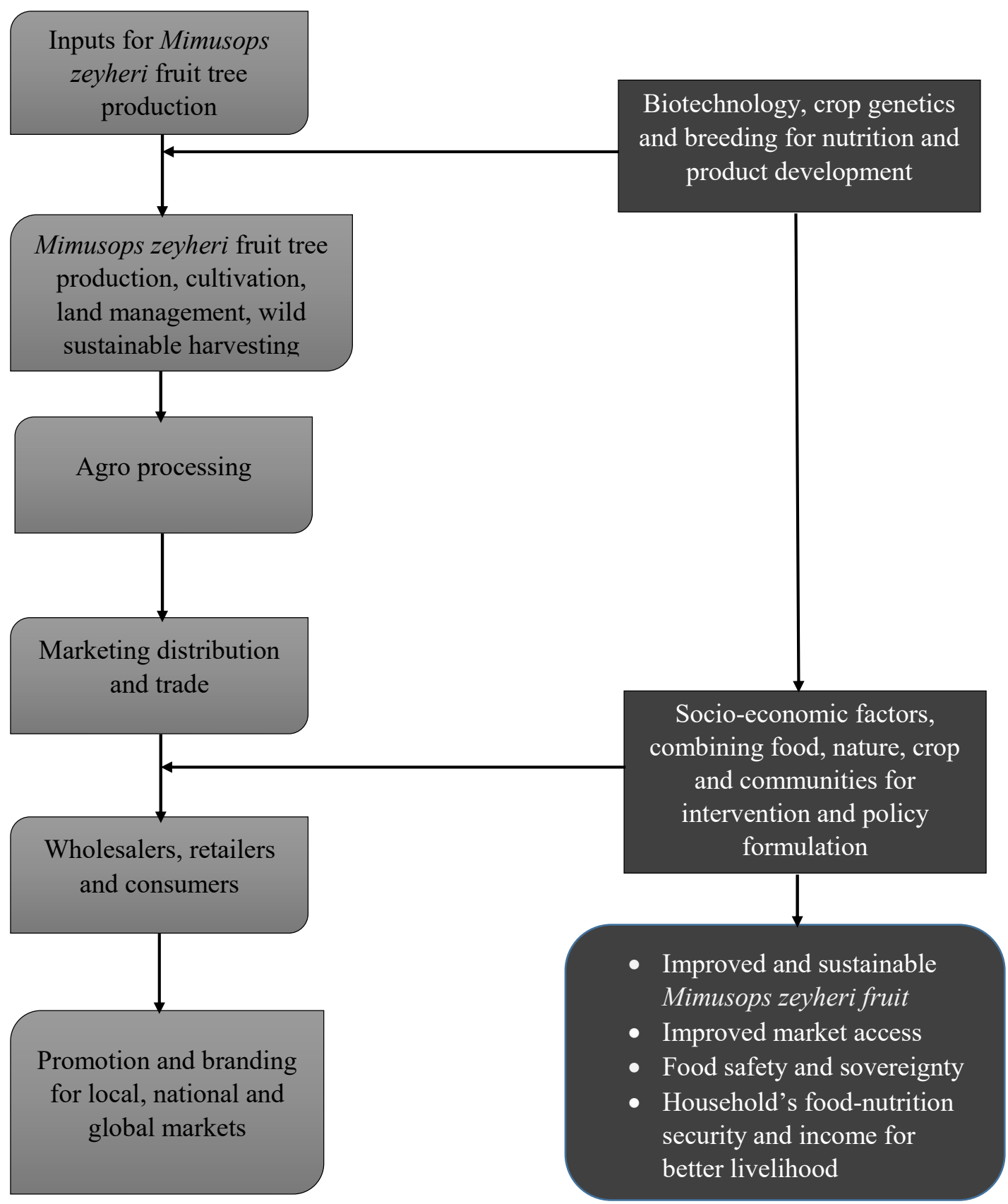

Figure 3. Potential value chain for the undervalued Mimusops zeyheri. 


\subsection{Application of Appropriate Biotechnological Methods for Plant Improvement and Cultivation}

From a molecular perspective, Mimusops zeyheri is currently under-studied. A starting point could be to collect the range of Mimusops zeyheri varieties for development as well as to characterize them as a principal source of primary germplasm. Considering the urgent need for food-nutrition as well as the need for an immediate intervention to increase agro-biodiversity, Mimusops zeyheri could form a significant source of accessible plant genetic resource(s). Generally, there is a need to fully elucidate the intra-and inter-genetic relationship in wild plants as well as the identification of unique attributes existing across different geographic populations using relevant biotechnological tools [51,52].

In southern Africa, the genetic diversity of Mimusops zeyheri remains anecdotal despite the biodiversity potential of the region. This may be due to the poor documentation of the genetic diversity of indigenous resources in the region and the continent at large [52,53]. There is a need to assess the current genetic diversity for Mimusops zeyheri to facilitate its conservation and development. Even though Mimusops zeyheri possesses several attributes that could drive rural communities and agricultural development, the lack of adequate information and research has created a disincentive for possible interventions [44]. This also affects the development, investment, and entry into formal market systems.

Furthermore, the genetic variations within Mimusops zeyheri accessions can potentially create a problem of heterogeneity. Hence, biotechnological tools together with conventional crop genetics, breeding techniques as well as de novo domestication can be employed for the rapid genetic improvement of Mimusops zeyheri. Agricultural biosciences and innovation need to be strengthened to ensure food security, enhance nutrition, and improve health in developing countries. Therefore, unlocking the resource value of Mimusops zeyheri to meet the needs of potential consumers remains pertinent. The need for cheap, affordable, and accessible fruits presents opportunities for developing countries to capitalize on their biodiversity by exploring the resource value of their indigenous fruit trees including Mimusops zeyheri to capture niche markets.

\section{Concluding Remarks}

Mimusops zeyheri has been traditionally used by rural peoples in southern Africa. Based on the rich pool of nutrients in the fruit, it remains an affordable, accessible, and nutritionally superior alternative to some relatively expensive "exotic" fruits. Evidence also suggests that Mimusops zeyheri has the potential to meet the immediate nutritional requirement as it is edible in the fresh stage upon harvesting. This strongly suggests its ability in providing dietary diversity, especially in resource-limited communities. In addition, the agroforestry benefits of this fruit tree to the smallholder farmers could contribute toward increased farm productivity and reduction of farm inputs such as organic fertilizers, pesticides, and herbicides. Based on preliminary data, the commercial potential of the oil from Mimusops zeyheri seeds needs to be further explored. However, several challenges associated with the potential commercialization of the fruit tree currently exist. Some of these include inadequate information on the effective cultivation protocols and agronomic aspects, lack of holistic research approach as well as inadequate political will and policy framework. Prospects of unlocking the potential of Mimusops zeyheri fruit tree need to include effective value-chain, effective agro-processing, and application of appropriate biotechnological methods for plant improvement and cultivation. Overall, the successful implementation of an ideal Mimusops zeyheri fruit requires multidisciplinary research that covers fields and expertise in plant breeding, micropropagation, and agronomy as well as pharmaceutical, toxicological, and phytochemical aspects. There is also a need for appropriate socio-economic and marketing policies. Finally, sufficient investments by governments, non-governmental organizations, and other relevant stakeholders remain pertinent.

Author Contributions: A.O.O. and E.J.I. conceptualized the project and wrote the draft manuscript with input from A.I.O. A.O.A. supervised and provided technical directive to improve the manuscript. All authors have read and agreed to the published version of the manuscript. 
Funding: Financial support from North-West University is appreciated. The article processing charge (APC) was paid by the North-West University, Mmabatho, South Africa.

Acknowledgments: A.O.O. appreciates the postdoctoral fellowship from North-West University, South Africa. All authors of this work appreciate their respective institutions for the enabling environment in which to conduct the research.

Conflicts of Interest: We declare that there are no conflicts of interest.

\section{References}

1. FAO; IFAD; UNICEF; WFP; WHO. The State of Food Security and Nutrition in the World 2019 Safeguarding Against Economic Slowdowns and Downturns; FAO: Rome, Italy, 2019.

2. Mayer, T.; Anderson, M.D. Food Insecurity: A Matter of Justice, Sovereignty, and Survival; Routledge: New York, NY, USA, 2020.

3. Buse, K.; Hawkes, S. Health in the sustainable development goals: Ready for a paradigm shift? Glob. Health 2015, 11, 13. [CrossRef]

4. FAO; IFAD; UNICEF; WFP; WHO. The State of Food Security and Nutrition in the World 2018: Building Climate Resilience for Food Security and Nutrition; FAO: Rome, Italy, 2018.

5. Ewing, M.; Msangi, S. Biofuels production in developing countries: Assessing tradeoffs in welfare and food security. Environ. Sci. Policy 2009, 12, 520-528. [CrossRef]

6. Shiferaw, B.; Prasanna, B.M.; Hellin, J.; Bänziger, M. Crops that feed the world 6. Past successes and future challenges to the role played by maize in global food security. Food Secur. 2011, 3, 307. [CrossRef]

7. Chivandi, E.; Mukonowenzou, N.; Berliner, D. The coastal red-milkwood (Mimusops caffra) seed: Proximate, mineral, amino acid and fatty acid composition. S. Afr. J. Bot. 2016, 102, 137-141. [CrossRef]

8. King, J.C.; Blumberg, J.; Ingwersen, L.; Jenab, M.; Tucker, K.L. Tree nuts and peanuts as components of a healthy diet. J. Nutr. 2008, 138, 1736S-1740S. [CrossRef] [PubMed]

9. Ros, E. Health benefits of nut consumption. Nutrients 2010, 2, 652-682. [CrossRef] [PubMed]

10. Tuso, P.J.; Ismail, M.H.; Ha, B.P.; Bartolotto, C. Nutritional update for physicians: Plant-based diets. Perm. J. 2013, 17, 61. [CrossRef] [PubMed]

11. Shackleton, S.; Shackleton, C.; Netshiluvhi, T.; Geach, B.; Ballance, A.; Fairbanks, D. Use patterns and value of savanna resources in three rural villages in South Africa. Econ. Bot. 2002, 56, 130-146. [CrossRef]

12. Omotayo, A.O.; Ndhlovu, P.T.; Tshwene, S.C.; Aremu, A.O. Utilization pattern of indigenous and naturalized plants among some selected rural households of North West Province, South Africa. Plants 2020, 9, 953. [CrossRef]

13. Fentahun, M.T.; Hager, H. Exploiting locally available resources for food and nutritional security enhancement: Wild fruits diversity, potential and state of exploitation in the Amhara region of Ethiopia. Food Secur. 2009, 1, 207. [CrossRef]

14. Boedecker, J.; Termote, C.; Assogbadjo, A.E.; van Damme, P.; Lachat, C. Dietary contribution of wild edible plants to women's diets in the buffer zone around the Lama forest, Benin-an underutilized potential. Food Secur. 2014, 6, 833-849. [CrossRef]

15. Moher, D.; Liberati, A.; Tetzlaff, J.; Altman, D.G. Preferred reporting items for systematic reviews and meta-analyses: The PRISMA statement. Ann. Intern. Med. 2009, 151, 264-266. [CrossRef]

16. Lemmens, R.H.M.J. Mimusops Zeyheri Sond; Plant Resources of Tropical Africa/Ressources végétales de l'Afrique Tropicale: Wageningen, The Netherlands, 2005.

17. Harris, B.J. Secondary Industrialisation in South Africa. In The Political Economy of the Southern African Periphery; Springer: Berlin/Heidelberg, Germany, 1993; pp. 17-51.

18. Fabricius, C. The fundamentals of community-based natural resource management. In Rights Resources and Rural Development; Taylor \& Francis Group: Milton, UK, 2013; pp. 18-58.

19. Deutschländer, M.S.; Lall, N.; van de Venter, M. Plant species used in the treatment of diabetes by South African traditional healers: An inventory. Pharm. Biol. 2009, 47, 348-365. [CrossRef]

20. Manning, J. Southern African Wild Flowers-Jewels of the Veld; Penguin Random House: Johannesburg, South Africa, 2013.

21. Mashela, P.W.; Mollel, N. Farmer-identified indigenous fruit tree with suitable attributes for the semi-arid Northern Province of South Africa. S. Afr. J. Agric. Ext. 2001, 30, 1-12. 
22. Hankey, A. Mimusops Zeyher Sond. (Sapotaceae). 2005. Available online: http://pza.sanbi.org/mimusopszeyheri (accessed on 30 October 2020).

23. Lapeña, I.; Turdieva, M.; Noriega, I.; Ayad, W. Conservation of fruit tree diversity in Central Asia: Policy options and challenges. In Conservation of Fruit Tree Diversity in Central Asia: Policy Options Challenges; Bioversity International: Rome, Italy, 2014.

24. De Wet, H.; Nzama, V.; Van Vuuren, S.F. Medicinal plants used for the treatment of sexually transmitted infections by lay people in northern Maputaland, KwaZulu-Natal Province, South Africa. S. Afr. J. Bot. 2012, 78, 12-20. [CrossRef]

25. Mngadi, S.V. Elemental Composition and Nutritional Value of the Edible Fruits of Coastal Red Milkwood (Mimusops caffra) and Transvaal Red Milkwood (Mimusops zeyheri) and the Impact of Soil Quality; University of KwaZulu-Natal: Durban, South Africa, 2017.

26. Mashela, P.W.; Tseke, P.E.; Pofu, K.M.; Mafeo, T.P. Potential commercialisation of Mimusops zeyheri: An indigenous tree selected for research and development through indigenous knowledge systems. In Proceedings of the 11th African Crop Science Proceedings, Sowing Innovations for Sustainable Food and Nutrition Security in Africa, Entebbe, Uganda, 14-17 October 2013; Volume 11, pp. 667-669.

27. Choat, B.; Jansen, S.; Brodribb, T.J.; Cochard, H.; Delzon, S.; Bhaskar, R.; Bucci, S.J.; Feild, T.S.; Gleason, S.M.; Hacke, U.G. Global convergence in the vulnerability of forests to drought. Nature 2012, 491, 752-755. [CrossRef]

28. Okatchi, H.; Raletamo, K.; Marobela, K. Determination of potentially toxic heavy metals in traditionally used medicinal plants for HIV/AIDS opportunistic infections in Ngamiland District in Northern Botswana. J. Anal. Chim. Acta 2012, 730, 42-48. [CrossRef]

29. Wilson, A.; Downs, C. Fruit nutritional composition and non-nutritive traits of indigenous South African tree species. S. Afr. J. Bot. 2012, 78, 30-36. [CrossRef]

30. Song, B.C.; Joo, N.-S.; Aldini, G.; Yeum, K.-J. Biological functions of histidine-dipeptides and metabolic syndrome. Nutr. Res. Pract. 2014, 8, 3-10. [CrossRef]

31. Mngadi, S.; Moodley, R.; Jonnalagadda, S.B. Elemental composition and nutritional value of the edible fruits of Transvaal red milkwood (Mimusops zeyheri) and impact of soil quality. Environ. Monit. Assess. 2019, 191, 135. [CrossRef]

32. Chivandi, E.; Mukonowenzou, N.; Nyakudya, T.; Erlwanger, K.H. Potential of indigenous fruit-bearing trees to curb malnutrition, improve household food security, income and community health in Sub-Saharan Africa: A review. Food Res. Int. 2015, 76, 980-985. [CrossRef]

33. Chivandi, E.; Davidson, B.; Pretorius, B.; Erlwanger, K. Proximate, mineral, amino acid, fatty acid, vitamin E, phytate phosphate and fibre composition of Mimusops zeyheri (Red Milkwood) seed. Int. J. Food Sci. Technol. 2011, 46, 555-560. [CrossRef]

34. Omotayo, A.O.; Aremu, A.O. Underutilized African indigenous fruit trees and food-nutrition security: Opportunities, challenges, and prospects. Food Energy Secur. 2020, e220, 1-16. [CrossRef]

35. Chivandi, E.; Davidson, B.C.; Erlwanger, K.H. A comparison of the lipid and fatty acid profiles from the kernels of the fruit (nuts) of Ximenia caffra and Ricinodendron rautanenii from Zimbabwe. Ind. Crop. Prod. 2008, 27, 29-32. [CrossRef]

36. Venter, F.; Venter, J.A. Making the Most of Indigenous Trees; Briza: Pretoria, South Africa, 1996.

37. Moustafa, H.; Amal, M.; Mohamed, R.; Eman, G. A review on phenolic compounds from family Sapotaceae. J. Pharmacogn. Phytochem. 2016, 5, 280-287.

38. Mojeremane, W.; Tshwenyane, S. Azanza garckeana: A valuable edible indigenous fruit tree of Botswana. Pak. J. Nutr. 2004, 3, 264-267.

39. Chivandi, E. In Vitro and In Vivo Chemical Characterization of Kigelia africana, Mimusops zeyheri, Terminalia sericea and Ximenia caffra Nuts and Nut Meals. Ph.D. Thesis, University of the Witwatersrand, Johannesburg, South Africa, 2013.

40. Akinnifesi, F.K.; Ajayi, O.C.; Sileshi, G.; Kadzere, I.; Akinnifesi, A.I. Domesticating and commercializing indigenous fruit and nut tree crops for food security and income generation in Sub-Saharan Africa. In Proceedings of the New Crops International Symposium, Southampton, UK, 3-4 September 2007.

41. Tchoundjeu, Z.; Asaah, E.K.; Anegbeh, P.; Degrande, A.; Mbile, P.; Facheux, C.; Tsobeng, A.; Atangana, A.R.; Ngo-Mpeck, M.L.; Simons, A.J. Putting participatory domestication into practice in West and Central Africa. For. Trees Livelihoods 2006, 16, 53-69. [CrossRef] 
42. Baldermann, S.; Blagojević, L.; Frede, K.; Klopsch, R.; Neugart, S.; Neumann, A.; Ngwene, B.; Norkeweit, J.; Schröter, D.; Schröter, A. Are neglected plants the food for the future? Crit. Rev. Plant Sci. 2016, 35, 106-119. [CrossRef]

43. Dube, Z.P.; Mashela, P.W.; Mathabatha, R.V. Mediterranean fruit fly on Mimusops zeyheri indigenous to South Africa: A threat to the horticulture industry. Pest Manag. Sci. 2016, 72, 1517-1520. [CrossRef]

44. Van Wyk, B.-E. The potential of South African plants in the development of new medicinal products. S. Afr. J. Bot. 2011, 77, 812-829. [CrossRef]

45. Fischer, J.; Lindenmayer, D.B. The conservation value of paddock trees for birds in a variegated landscape in southern New South Wales. 2. Paddock trees as stepping stones. Biodivers. Conserv. 2002, 11, 833-849. [CrossRef]

46. Leakey, R.R. Potential for novel food products from agroforestry trees: A review. Food Chem. 1999, 66, 1-14. [CrossRef]

47. Power, E.M. Conceptualizing food security for Aboriginal people in Canada. Can. J. Public Health 2008, 99, 95-97. [CrossRef] [PubMed]

48. Mhazo, N.; Mvumi, B.M.; Nyakudya, E.; Nazare, R.M. The status of the agro-processing industry in Zimbabwe with particular reference to small-and medium-scale enterprises. Afr. J. Agric. Res. 2012, 7, 1607-1622.

49. FAO; UNIDO. Agricultural Mechanization in Africa. Time for Action; FAO: Vienna, Austria, 2008.

50. Edington, J. Indigenous Environmental Knowledge: Reappraisal; Springer: Berlin/Heidelberg, Germany, 2017.

51. Mabhaudhi, T.; Chimonyo, V.G.; Modi, A.T. Status of underutilised crops in South Africa: Opportunities for developing research capacity. Sustainability 2017, 9, 1569. [CrossRef]

52. Daru, B.H.; Berger, D.K.; Wyk, A.E. Opportunities for unlocking the potential of genomics for African trees. New Phytol. 2016, 210, 772-778. [CrossRef] [PubMed]

53. Dawson, I.K.; Leakey, R.; Clement, C.R.; Weber, J.C.; Cornelius, J.P.; Roshetko, J.M.; Vinceti, B.; Kalinganire, A.; Tchoundjeu, Z.; Masters, E.; et al. The management of tree genetic resources and the livelihoods of rural communities in the tropics: Non-timber forest products, smallholder agroforestry practices and tree commodity crops. For. Ecol. Manag. 2014, 333, 9-21. [CrossRef]

Publisher's Note: MDPI stays neutral with regard to jurisdictional claims in published maps and institutional affiliations.

(C) 2020 by the authors. Licensee MDPI, Basel, Switzerland. This article is an open access article distributed under the terms and conditions of the Creative Commons Attribution (CC BY) license (http://creativecommons.org/licenses/by/4.0/). 